\title{
Diversidade genética em genótipos de milho de plantio tardio sob diferentes níveis de nitrogênio no Tocantins
}

\section{Karen Cristina Leite Silva ${ }^{1}$, Weder Ferreira dos Santos ${ }^{1}$, Flávio Sérgio Afférri ${ }^{2}$, Joenes Mucci Peluzio $^{3}$, Layanni Ferreira Sodré ${ }^{1}$}

\author{
${ }^{1}$ Universidade Federal do Tocantins, Campus Universitário de Gurupi, Gurupi, Tocantins, Brasil. E-mail: karencris.31@ gmail.com, \\ eng.agricola.weder@gmail.com, farm.layannisd@gmail.com \\ ${ }^{2}$ Universidade Federal de São Carlos, Campus São Carlos, São Carlos, São Paulo, Brasil. E-mail: flavioafferri@gmail.com \\ ${ }^{3}$ Universidade Federal do Tocantins, Campus de Palmas, Palmas, Tocantins, Brasil. E-mail: joenesp@mail.uft.edu.br
}

Recebido: 06/12/2017; Aceito: 26/03/2019.

\section{RESUMO}

O estudo da diversidade genética é importante para os programas de melhoramento genético, pois a variabilidade existente entre os genótipos é uma estratégia para obter ganhos de seleção nos cruzamentos. Objetivou-se com este trabalho avaliar a divergência genética de genótipos de milho com uso de dados de seis ensaios na Região Central do Estado do Tocantins, distribuídos em duas épocas de semeadura (21/01/2014 e 19/02/2014). Em cada época, os ensaios foram realizados sob condições de alto, médio e baixo fornecimento de adubação nitrogenada de cobertura. Na aplicação da técnica de agrupamento dos genótipos, foi adotada a distância generalizada de Mahalanobis $\left(\mathrm{D}^{2}\right)$ como medida de dissimilaridade. Os genótipos 7 e 10 foram produtivos e apresentaram maior distância genética $\left(D^{2}=79,2\right)$. Houve a formação de quatro grupos distintos. As características peso da espiga com palha, altura da planta e altura da espiga foram as que mais contribuíram para a divergência genética.

Palavras-chave: Análise multivariada, cerrado, dissimilaridade genética, Zea mays.

\section{Genetic diversity in late sowing maize genotypes under different nitrogen levels in Tocantins State, Brazil}

\begin{abstract}
The study of genetic diversity is important for genetic breeding programs, since the variability among genotypes is a strategy to obtain selection gains in crosses. The objective of this work was to evaluate the genetic divergence of maize genotypes using data from six trials in the Central Region of the State of Tocantins, distributed in two sowing dates (01/21/2014 and 02/19/2014). In each season, the tests were performed under conditions of high, medium and low nitrogen fertilizer coverage. In the application of the genotype grouping technique, the generalized distance of Mahalanobis $\left(\mathrm{D}^{2}\right)$ was adopted as a measure of dissimilarity. Genotypes 7 and 10 were productive and showed greater genetic distance $\left(\mathrm{D}^{2}=79.2\right)$. There were four different groups formed. The characteristics of the tang with straw, plant height and ear height were the main contributors to genetic divergence.
\end{abstract}

Keywords: Multivariate analysis, cerrado, genetic dissimilarity, Zea mays. 


\section{Introdução}

A cultura do milho (Zea mays L.) é uma das mais importantes do Brasil, sendo produzida em todo o território nacional (Silva et al., 2015) e cultivada tanto com vistas para a agricultura familiar quanto para o mercado, envolvendo grandes empresas agropecuárias, uma vez que apresenta importância social, nutricional e agroindustrial (Borém et al., 2017).

Em um programa de melhoramento, o primeiro passo consiste na escolha dos progenitores, pois a partir deles serão gerados os materiais almejados pelo melhorista. Segundo Barros et al. (2012), a avaliação de genótipos visando à identificação e recomendação de materiais superiores em diferentes ambientes é considerada por muitos autores como uma das etapas mais importantes, trabalhosa e onerosa, dentro do programa. A utilização de diferentes doses de $\mathrm{N}$ em cobertura visa à "criação" dos diferentes ambientes, possibilitando a análise multivariada.

A variabilidade genética, já muito explorada nos últimos anos, principalmente na cultura do milho, tem mostrado sua importante valia através dos trabalhos de melhoramento genético e de seus bons resultados. As populações de polinização aberta ou variedades, apesar de serem menos produtivas que os cultivares modernos (híbridos), têm a expressão de uma complexa estrutura genética e, por isso, são importantes fontes de variabilidade (Coimbra et al., 2010).

O estudo da diversidade genética através da análise multivariada é importante para os programas de melhoramento genético, pois a variabilidade existente entre os genótipos é fundamental para se obter ganhos de seleção nos cruzamentos de grupos geneticamente divergentes que apresentam características de interesse (Cruz et al., 2011).

Existem duas maneiras de se inferir sobre a divergência genética: de forma quantitativa e de forma preditiva. Entre as de natureza quantitativa, citam-se as análises dialélicas, onde se fazem necessários os cruzamentos entre os genitores para sua posterior avaliação. As de natureza preditiva levam em conta as diferenças morfológicas, qualidade nutricional, fisiológicas ou moleculares, quantificadas em alguma medida de dissimilaridade que possa expressar o grau de diversidade genética entre os genitores (Cruz et al., 2012).

Entre as diversas medidas de dissimilaridade propostas para a quantificação das distâncias entre genótipos, a distância generalizada de Mahalanobis tem sido a mais amplamente utilizada quando se dispõem de experimentos com repetições (Simon et al., 2012). Esta se diferencia das demais técnicas por levar em consideração as correlações entre os caracteres avaliados (Cruz et al., 2012). Diante do exposto, o presente trabalho foi realizado com o intuito de identificar genótipos de milho potencialmente promissores para cultivo, na região central do Estado do Tocantins, para utilizá-los em futuro esquema de cruzamento dialélico.

\section{Material e Métodos}

No ano de 2014, foram realizados seis ensaios de genótipos de milho no Centro Agrotecnológico da Universidade Federal do Tocantins (UFT), Campus de Palmas (220 m, 10 $45^{\prime} \mathrm{S}$ e $47^{\circ} 14^{\prime} \mathrm{O}$ ), em solo do tipo Latossolo Vermelho Amarelo distrófico. A análise do solo da área em estudo, na camada de 0-0,20 cm, apresentou os seguintes resultados: $\mathrm{pH}\left(\mathrm{CaCl}_{2}\right)=5,50$; $\mathrm{P}$ (método Mehlich $\left.^{-1}\right)=18,30 \mathrm{mg} \mathrm{dm}^{-3} ; \mathrm{Ca}+\mathrm{Mg}$ (Método $\mathrm{KCl} 1 \mathrm{~mol} \mathrm{~L}^{-1}$ ), $\mathrm{H}+\mathrm{Al}$ (Método $\mathrm{Ca}(\mathrm{OAc})_{2}$ 0,5 $\mathrm{mol} \mathrm{L}^{-1}$ ), K (método Mehlich-1 $)=3,30 ; 2,10 ; 0,10 \mathrm{cmol}_{\mathrm{c}}$ $\mathrm{dm}^{-3}$, respectivamente; CTC $=5,50 \mathrm{cmol}_{\mathrm{c}} \mathrm{dm}^{-3} ; \mathrm{V}=$ 61,82\%; Matéria orgânica (Método Walkley e Black) = $18,00 \mathrm{~g} \mathrm{dm}^{-3}$; Areia, Silte e Argila = 750, 50 e $200 \mathrm{~g} \mathrm{~kg}^{-}$ 1. Os dados meteorológicos (Umidade relativa, Temperatura, Precipitação pluviométrica) durante o período de condução dos experimentos estão representados na Figura 1.

Os ensaios foram instalados em duas épocas de semeadura, sendo que em cada época os genótipos foram cultivados sob condições de alto $\left(140 \mathrm{~kg} \mathrm{ha}^{-1}\right)$, médio $\left(80 \mathrm{~kg} \mathrm{ha}^{-1}\right)$ e baixo $\left(0 \mathrm{~kg} \mathrm{ha}^{-1}\right)$ fornecimento de nitrogênio (N) em cobertura. As adubações nos ambientes de baixo, médio e alto $\mathrm{N}$ correspondem à menor, média e maior faixa esperada de produtividade de grãos (Ribeiro et al., 1999). A semeadura foi realizada em 21 de janeiro para a primeira época (1), e em 19 de fevereiro para a segunda época (2).

Os ambientes foram denominados de acordo com o fornecimento de nitrogênio e a época de semeadura. Portanto, o ambiente 01 recebeu $0 \mathrm{~kg} \mathrm{ha}^{-1}$ de nitrogênio e foi semeado na primeira época, o ambiente 81 recebeu $80 \mathrm{~kg} \mathrm{ha}^{-1} \mathrm{e}$ foi semeado na primeira época, o ambiente 142 recebeu $140 \mathrm{~kg} \mathrm{ha}^{-1}$ e foi semeado na segunda época, e assim sucessivamente para os demais ambientes.

O delineamento experimental utilizado em cada ensaio foi em blocos ao acaso com doze tratamentos e três repetições. Os tratamentos foram constituídos por 12 genótipos de polinização aberta oriundos do programa de melhoramento de milho da UFT, sendo denominados: GEN 1, GEN 2, GEN 3, GEN 4, GEN 5, GEN 6, GEN 7, GEN 8, GEN 9, GEN 10, GEN 11 e GEN 12.

A parcela experimental foi representada por quatro linhas de cinco metros lineares, espaçadas por $0,90 \mathrm{~m}$ entre linhas. Na colheita, foram utilizadas as duas linhas centrais de cada parcela, descartando-se $0,50 \mathrm{~m}$ das extremidades das linhas. 


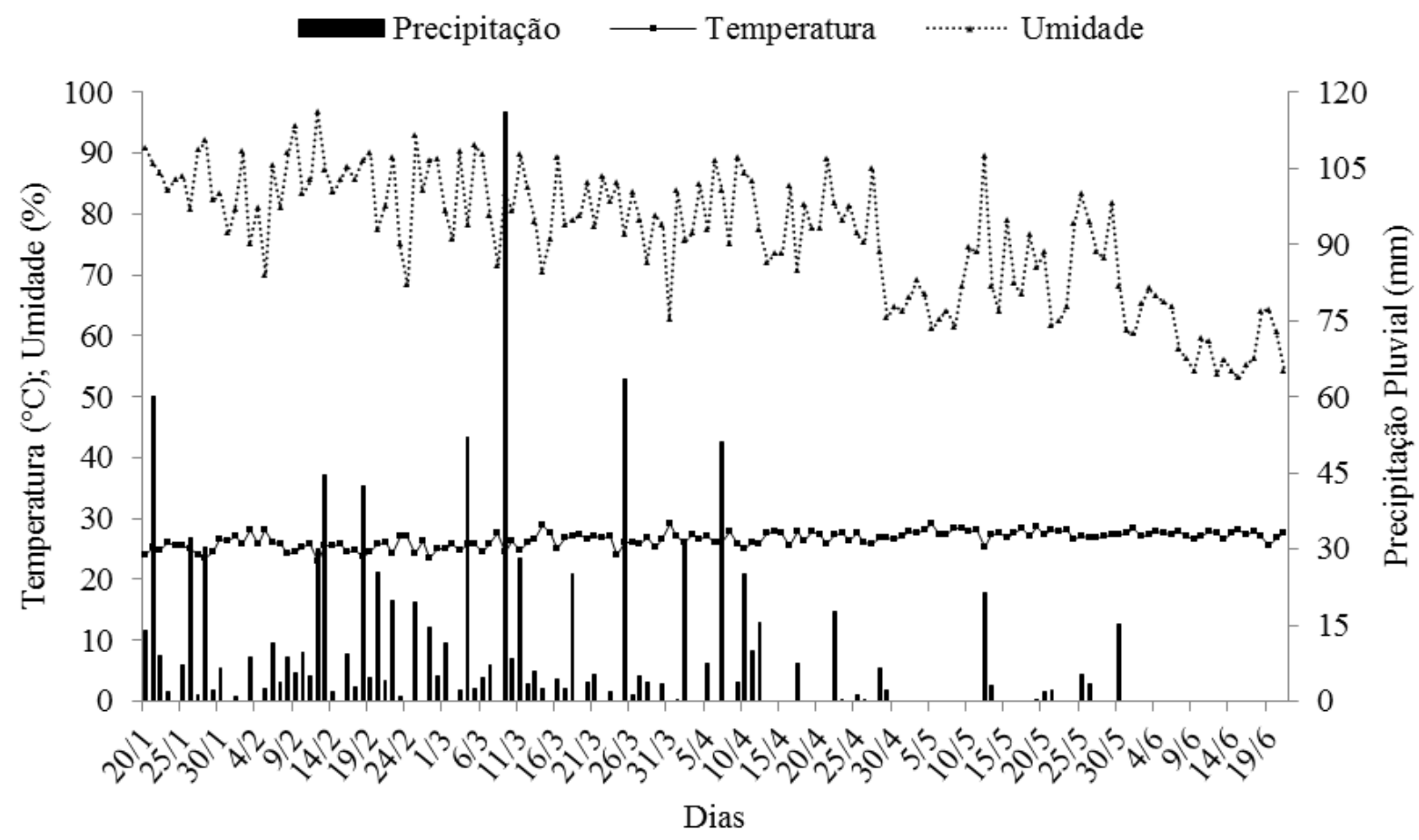

Figura 1. Variação diária da temperatura, precipitação pluvial e umidade relativa de 20/01/2014 a 21/06/2014, Palmas-TO. Fonte: Dados da Rede do INMET.

Utilizou-se o sistema de preparo de solo tipo convencional, com uma gradagem seguida do nivelamento da área. O plantio e a adubação de présemeadura foram realizados manualmente, utilizando $300 \mathrm{~kg} \mathrm{ha}^{-1}$ de NPK de 5-25-15+0,5\% Zn para todos os ensaios. A semeadura foi realizada com o intuito de se obter 55.555 plantas ha $^{-1}$.

A adubação de cobertura foi realizada apenas com $\mathrm{N}$ no estádio V6 (seis folhas completamente abertas), com uso de ureia $(48 \%$ de N). A dosagem foi de 0,80 e 140 $\mathrm{kg} \mathrm{ha}^{-1}$ de $\mathrm{N}$ para os ambientes de baixo, médio e alto $\mathrm{N}$, respectivamente.

Os tratos culturais, como o controle fitossanitário contra doenças, pragas e plantas daninhas foram realizados seguindo as recomendações técnicas da cultura do milho, de acordo com Borém et al. (2017).

Foram avaliadas as seguintes características: 1) altura de plantas $(\mathrm{AP})(\mathrm{cm}) ; 2)$ altura de espiga (AE) $(\mathrm{cm})$; 3) número de folhas totais na planta $(\mathrm{NF})$; 4) número de folhas acima da espiga principal (NFAE); 5) massa da espiga com palha (MECP) (g); 6) massa da espiga sem palha (MESP) (g); 7) diâmetro da espiga (DE) $(\mathrm{mm})$; 8) comprimento de espiga (CE) (cm); 9) número de fileiras de grãos (NFG); 10) número de grãos por fileira (NGF); 11) diâmetro do sabugo (DS) (mm); 12) umidade dos grãos (UMI); 13) largura do grão (LG) $(\mathrm{mm})$; 14) comprimento do grão (CG) $(\mathrm{mm})$; 15) altura do grão $(\mathrm{AG})(\mathrm{mm})$; 16) produtividade de grãos por planta (PGPL) (g).
Foi realizada a análise de variância de cada ensaio e, posteriormente, a análise conjunta dos ensaios, em que o menor quadrado médio residual não diferiu em mais de sete vezes do maior (Cruz et al., 2011). As médias dos tratamentos foram comparadas pelo teste de Scott e Knott (1974) ao nível de 5\% de significância após ser testada a normalidade dos dados pelo teste de Kolmogorov-Smirnov. Foi realizado estudo da divergência genética geral, considerando os dados médios dos seis ensaios, sendo utilizada a distância generalizada de Mahalanobis $\left(\mathrm{D}^{2}\right)$ como medida de dissimilaridade, levando em consideração o grau de dependência entre as variáveis estudadas. Para $\mathrm{o}$ estabelecimento de grupos similares, foi aplicado o método hierárquico aglomerativo de otimização proposto por Tocher (Rao, 1952), cujos cálculos foram igualmente embasados na distância generalizada de Mahalanobis. Também foi utilizado o critério de Singh (1981) para quantificar a contribuição relativa das características avaliadas na divergência genética.

\section{Resultados e Discussão}

A análise de variância conjunta não revelou efeito significativo $(p<0,05)$ para os genótipos e ensaios quanto às características NFG, NGF, LG, CG e AG. Os genótipos (GEN) 8, 10 e 12 foram os que apresentaram maior número de médias classificadas no grupo estatístico superior (Tabela 1). 
Tabela 1. Resumo das médias dos 12 genótipos de milho para as características altura de plantas (AP), altura de espiga (AE), número de folhas totais na planta (NF), número de folhas acima da espiga principal (NFAE), massa da espiga com palha (MECP), massa da espiga sem palha (MESP), diâmetro da espiga (DE), comprimento de espiga (CE), número de fileiras de grãos (NFG), número de grãos por fileira (NGF), diâmetro do sabugo (DS), umidade dos grãos (UMI), largura do grão (LG), comprimento do grão (CG), altura do grão (AG), produtividade de grãos por planta (PGPL). Palmas-TO, 2014.

\begin{tabular}{|c|c|c|c|c|c|c|c|c|}
\hline Genótipos & $\mathrm{AP}(\mathrm{cm})$ & $\mathrm{AE}(\mathrm{cm})$ & NF & NFAE & $\operatorname{MECP}(\mathrm{g})$ & $\operatorname{MESP}(\mathrm{g})$ & $\mathrm{DE}(\mathrm{mm})$ & $\mathrm{CE}(\mathrm{cm})$ \\
\hline 1 & $148 \mathrm{c}$ & $76 \mathrm{~b}$ & $12,0 \mathrm{a}$ & $7 \mathrm{a}$ & $145,6 \mathrm{c}$ & $124,8 \mathrm{~b}$ & $34,6 \mathrm{a}$ & $13,8 \mathrm{~b}$ \\
\hline 2 & $160 \mathrm{~b}$ & $76 \mathrm{~b}$ & $11,1 \mathrm{a}$ & $6 \mathrm{~b}$ & $141,0 \mathrm{c}$ & $123,7 \mathrm{~b}$ & $35,5 \mathrm{a}$ & $13,5 \mathrm{~b}$ \\
\hline 3 & $163 \mathrm{~b}$ & $76 \mathrm{~b}$ & $11,1 \mathrm{a}$ & $6 \mathrm{~b}$ & $127,1 \mathrm{~d}$ & $115,9 \mathrm{~b}$ & $35,0 \mathrm{a}$ & $13,1 \mathrm{~b}$ \\
\hline 4 & $163 \mathrm{~b}$ & $80 \mathrm{~b}$ & $11,0 \mathrm{a}$ & $6 \mathrm{~b}$ & $122,3 \mathrm{~d}$ & $108,6 \mathrm{~b}$ & $33,1 \mathrm{~b}$ & $13,7 \mathrm{~b}$ \\
\hline 5 & $165 \mathrm{~b}$ & 84 a & $11,3 \mathrm{a}$ & $6 \mathrm{~b}$ & $128,0 \mathrm{~d}$ & $114,0 \mathrm{~b}$ & $33,4 \mathrm{~b}$ & $13,9 \mathrm{~b}$ \\
\hline 6 & $152 \mathrm{c}$ & $75 \mathrm{~b}$ & $10,7 \mathrm{~b}$ & $6 \mathrm{~b}$ & $127,0 \mathrm{~d}$ & $116,7 \mathrm{~b}$ & $34,7 \mathrm{a}$ & $13,9 \mathrm{~b}$ \\
\hline 7 & $152 \mathrm{c}$ & $67 c$ & $9,9 \mathrm{~b}$ & $6 \mathrm{~b}$ & $107,8 \mathrm{~d}$ & $100,2 \mathrm{~b}$ & $32,2 \mathrm{~b}$ & $13,9 \mathrm{~b}$ \\
\hline 8 & $175 \mathrm{a}$ & $91 \mathrm{a}$ & $11,3 \mathrm{a}$ & $6 \mathrm{~b}$ & $161,8 \mathrm{~b}$ & 148,8 a & $36,2 \mathrm{a}$ & $14,1 \mathrm{~b}$ \\
\hline 9 & $142 \mathrm{c}$ & $64 \mathrm{c}$ & $10,5 \mathrm{~b}$ & $6 \mathrm{~b}$ & $120,3 \mathrm{~d}$ & $111,4 \mathrm{~b}$ & $33,6 \mathrm{~b}$ & $13,7 \mathrm{~b}$ \\
\hline 10 & $172 \mathrm{a}$ & $81 \mathrm{~b}$ & $11,0 \mathrm{a}$ & $6 \mathrm{~b}$ & $188,7 \mathrm{a}$ & 167,7 a & $35,8 \mathrm{a}$ & $15,7 \mathrm{a}$ \\
\hline 11 & $167 \mathrm{~b}$ & $80 \mathrm{~b}$ & $11,5 \mathrm{a}$ & $6 \mathrm{~b}$ & $137,4 \mathrm{c}$ & $127,5 \mathrm{~b}$ & $35,0 \mathrm{a}$ & $13,4 \mathrm{~b}$ \\
\hline 12 & $164 \mathrm{~b}$ & $77 \mathrm{~b}$ & $11,5 \mathrm{a}$ & $6 \mathrm{~b}$ & $169,7 \mathrm{~b}$ & $154,3 \mathrm{a}$ & $35,7 \mathrm{a}$ & $15,3 \mathrm{a}$ \\
\hline Média & 160 & 77 & 11 & 6 & 140 & 126 & 35 & 14 \\
\hline $\mathrm{CV}(\%)$ & 4 & 7 & 5 & 6 & 12 & 12 & 3 & 10 \\
\hline Genótipos & NFG & NGF & DS (mm) & UMI & LG (mm) & $\mathrm{CG}(\mathrm{mm})$ & $\mathrm{AG}(\mathrm{mm})$ & PGPL (g) \\
\hline 1 & $16 \mathrm{a}$ & $30 \mathrm{a}$ & $17,0 \mathrm{a}$ & $16,8 \mathrm{a}$ & $8,0 \mathrm{a}$ & $4,0 \mathrm{a}$ & $10,5 \mathrm{a}$ & $94,5 \mathrm{~b}$ \\
\hline 2 & $16 \mathrm{a}$ & $26 \mathrm{a}$ & $18,0 \mathrm{a}$ & $16,1 \mathrm{a}$ & 7,9 a & $4,2 \mathrm{a}$ & $10,3 \mathrm{a}$ & $95,3 \mathrm{~b}$ \\
\hline 3 & $14 \mathrm{a}$ & $26 \mathrm{a}$ & $17,4 \mathrm{a}$ & $15,5 \mathrm{a}$ & $7,6 \mathrm{a}$ & $3,8 \mathrm{a}$ & $10,2 \mathrm{a}$ & $87,1 \mathrm{~b}$ \\
\hline 4 & $14 \mathrm{a}$ & $32 \mathrm{a}$ & $18,3 \mathrm{a}$ & $13,8 \mathrm{~b}$ & $8,5 \mathrm{a}$ & $3,8 \mathrm{a}$ & 9,8 a & $88,8 \mathrm{~b}$ \\
\hline 5 & $14 \mathrm{a}$ & $31 \mathrm{a}$ & $17,4 \mathrm{a}$ & $15,1 \mathrm{~b}$ & $8,2 \mathrm{a}$ & $3,5 \mathrm{a}$ & 9,9 a & $91,9 \mathrm{~b}$ \\
\hline 6 & $14 \mathrm{a}$ & $28 \mathrm{a}$ & $18,0 \mathrm{a}$ & $14,8 \mathrm{~b}$ & 8,6 a & $4,0 \mathrm{a}$ & $10,5 \mathrm{a}$ & $92,9 \mathrm{~b}$ \\
\hline 7 & $14 \mathrm{a}$ & $27 \mathrm{a}$ & $17,0 \mathrm{a}$ & $13,6 \mathrm{~b}$ & $8,6 \mathrm{a}$ & $4,2 \mathrm{a}$ & $10,0 \mathrm{a}$ & $79,9 \mathrm{~b}$ \\
\hline 8 & $14 \mathrm{a}$ & $32 \mathrm{a}$ & $17,0 \mathrm{a}$ & $15,9 \mathrm{a}$ & $8,8 \mathrm{a}$ & $3,8 \mathrm{a}$ & $11,0 \mathrm{a}$ & $114,9 \mathrm{a}$ \\
\hline 9 & $14 \mathrm{a}$ & $26 \mathrm{a}$ & $18,3 \mathrm{a}$ & $16,3 \mathrm{a}$ & 8,6 a & $4,1 \mathrm{a}$ & 9,9 a & $81,7 \mathrm{~b}$ \\
\hline 10 & $16 \mathrm{a}$ & $33 a$ & $16,9 \mathrm{a}$ & $17,3 \mathrm{a}$ & 8,3 a & $4,0 \mathrm{a}$ & $10,8 \mathrm{a}$ & 123,9 a \\
\hline 11 & $14 \mathrm{a}$ & $29 a$ & $17,3 \mathrm{a}$ & $15,5 \mathrm{a}$ & $8,4 \mathrm{a}$ & $3,7 \mathrm{a}$ & $10,4 \mathrm{a}$ & $94,5 \mathrm{~b}$ \\
\hline 12 & $14 \mathrm{a}$ & $31 \mathrm{a}$ & $17,1 \mathrm{a}$ & $16,9 \mathrm{a}$ & 8,4 a & $4,0 \mathrm{a}$ & $10,6 \mathrm{a}$ & 119,7 a \\
\hline Média & 14 & 29 & 17 & 16 & 8 & 4 & 10 & 97 \\
\hline $\mathrm{CV}(\%)$ & 25 & 22 & 9 & 8 & 23 & 7 & 5 & 10 \\
\hline
\end{tabular}

Médias seguidas de mesmas letras, na coluna, não apresentam diferença significativa a 5\% de significância pelo teste de Scott-Knott.

Para a característica AP, os genótipos apresentaram valores de $142 \mathrm{~cm}$ (GEN 9) a $175 \mathrm{~cm}$ (GEN 8), classificados em três grupos estatísticos (Tabela 1). O grupo de maior média foi composto pelos genótipos GEN 8 e GEN 10, enquanto que o de menores médias foi composto pelos genótipos GEN 1, GEN 6, GEN 7 e GEN 9. A altura de plantas é um dos fatores que contribui na disponibilização de fotoassimilados para o enchimento dos grãos, que são translocados do colmo até a espiga. $\mathrm{O}$ nitrogênio $(\mathrm{N})$ atua sobre o crescimento vegetativo, influenciando diretamente a divisão e a expansão celular, consequentemente influenciando a altura da planta, além de influenciar no processo fotossintético (Lins et al., 2017).

Quanto à $\mathrm{AE}$, os valores variaram de $64 \mathrm{~cm}$ (GEN 9) a $91 \mathrm{~cm}$ (GEN 8), classificados em três grupos estatísticos (Tabela 1). Os genótipos 5 e 8 integraram o grupo de maior média. $\mathrm{O}$ grupo de menor média foi composto pelos genótipos 7 e 9. Alvarez et al. (2006) observaram que a altura de espiga está correlacionada com a altura de planta, portanto plantas mais altas tendem a apresentar, também, espigas mais altas, o que ocorreu para a maioria dos genótipos neste trabalho.

$\mathrm{O}$ genótipo 1 foi o que apresentou maior média estatística para as características NF e NFAE (Tabela 1). Em ambas as características houve a formação de dois grupos estatísticos. As folhas são responsáveis pelas trocas gasosas e pelo processo de fotossíntese nas plantas, produzindo fotoassimilados. Segundo Alvim et al. (2010), o suprimento de metabólitos nas diversas partes da planta é feito de forma diferente de acordo com as várias posições de inserção das folhas no caule. As folhas localizadas no terço superior do colmo são responsáveis por cerca de $50 \%$ dos carboidratos que são acumulados nos grãos de milho (Fornasieri Filho, 2007), daí a importância das folhas acima da espiga. 
As médias dos genótipos para a característica MECP variaram de 107,8 g (GEN 7) a 188,7 g (GEN 10), classificadas em quatro grupos estatísticos (Tabela 1). O genótipo 10 foi o único componente do grupo estatístico superior. O segundo grupo foi formado pelos genótipos 8 e 12; o terceiro, pelos genótipos 1,2 e 11 , enquanto que o grupo de menor média foi composto pelos genótipos 3, 4, 5, 6, 7 e 9. Quanto à MESP, as médias variaram de 100,2 g (GEN 7) a 167,7 g (GEN 10), classificadas em dois grupos estatísticos. Os genótipos 8, 10 e 12 foram componentes do grupo estatístico superior.

Quanto ao DE, as médias dos genótipos variaram de $33,1 \mathrm{~mm}(\mathrm{GEN} 4)$ a 36,1 mm (GEN 8), classificadas em dois grupos estatísticos (Tabela 1). Apenas os genótipos 4, 5, 7 e 9 foram classificados no grupo estatístico inferior. Esta característica está estreitamente relacionada com o enchimento de grãos e com o NFG, que também é influenciado pela genética da planta (Goes et al., 2012).

Com relação ao $\mathrm{CE}$, os genótipos foram diferenciados em dois grupos estatísticos (Tabela 1). As médias variaram de $13,1 \mathrm{~cm}$ (GEN 3) a $15,7 \mathrm{~cm}$ (GEN 10). Correlação positiva entre o $\mathrm{CE}$ e a $\mathrm{AP}$ foi observada por Albuquerque et al. (2008), portanto, a seleção para plantas mais altas pode resultar em espigas maiores e com maior peso. O CE pode interferir diretamente no NGF e, consequentemente, na PGPL do milho. Sendo assim, indica-se a escolha de cultivares com maior $\mathrm{CE}$, pois esse fator interfere diretamente em produtividades mais elevadas da cultura (Pizolato Neto et al., 2016).

Quanto ao DS, não foi observada diferença estatística entre os genótipos. As médias variaram de $16,9 \mathrm{~mm}$ (GEN 10) a 18,3 mm (GEN 4 e 9) (Tabela 1). Para a característica UMI, houve a formação de dois grupos estatísticos e as médias variaram de 13,6\% (GEN 7) a 17,3\% (GEN 10).

O genótipo 10 apresentou maior média para PGPL, seguido pelos genótipos 12 e 8 , também classificados no grupo estatístico superior (Tabela 1). Nota-se a influência de diversas características sobre a produção por planta, como diâmetro e comprimento da espiga, NFG e NGF, além de altura, comprimento e largura do grão.

Quanto às médias das características nos diferentes ambientes (Tabela 2), nota-se o aumento da maioria à medida que ocorreu o aumento das doses de $\mathrm{N}$ em cobertura nos ambientes da segunda época de plantio (ambientes 02, 82 e 142).

Tabela 2. Resumo das médias dos seis ensaios, para as características altura de plantas (AP), altura de espiga (AE), número de folhas totais na planta (NF), número de folhas acima da espiga principal (NFAE), massa da espiga com palha (MECP), massa da espiga sem palha (MESP), diâmetro da espiga (DE), comprimento de espiga (CE), número de fileiras de grãos (NFG), número de grãos por fileira (NGF), diâmetro do sabugo (DS), umidade dos grãos (UMI), largura do grão (LG), comprimento do grão (CG), altura do grão (AG), produtividade de grãos por planta (PGPL). Palmas-TO, 2014.

\begin{tabular}{|c|c|c|c|c|c|c|}
\hline \multirow{2}{*}{ Características } & \multicolumn{6}{|c|}{ Ambientes } \\
\hline & 01 & 81 & 141 & 02 & 82 & 142 \\
\hline $\mathrm{AP}$ & $154 \mathrm{~b}$ & $147 \mathrm{~b}$ & $168 \mathrm{a}$ & $156 \mathrm{~b}$ & $166 \mathrm{a}$ & $170 \mathrm{a}$ \\
\hline $\mathrm{AE}$ & $71 \mathrm{c}$ & $70 \mathrm{c}$ & $79 \mathrm{~b}$ & $78 \mathrm{~b}$ & $78 \mathrm{~b}$ & $88 \mathrm{a}$ \\
\hline NF & $10,8 \mathrm{~b}$ & $10,4 \mathrm{~b}$ & $11,5 \mathrm{a}$ & $11,1 \mathrm{a}$ & $10,9 \mathrm{~b}$ & $11,9 \mathrm{a}$ \\
\hline NFAE & $5,9 \mathrm{a}$ & $5,4 \mathrm{~b}$ & $6,1 \mathrm{a}$ & $5,8 \mathrm{a}$ & $6,3 \mathrm{a}$ & $6,3 \mathrm{a}$ \\
\hline PECP & $148,5 \mathrm{a}$ & $99,4 \mathrm{c}$ & $163,5 \mathrm{a}$ & $122,2 \mathrm{~b}$ & $158,1 \mathrm{a}$ & $146,6 \mathrm{a}$ \\
\hline PESP & $133,5 \mathrm{a}$ & $87,9 \mathrm{c}$ & 147,6 a & $110,7 \mathrm{~b}$ & $144,2 \mathrm{a}$ & $132,8 \mathrm{a}$ \\
\hline $\mathrm{DE}$ & $27,2 \mathrm{c}$ & $39,7 \mathrm{~b}$ & $27,7 \mathrm{c}$ & $42,0 \mathrm{a}$ & $27,0 \mathrm{c}$ & $43,5 \mathrm{a}$ \\
\hline $\mathrm{CE}$ & $14,2 \mathrm{a}$ & $12,0 \mathrm{~b}$ & $15,1 \mathrm{a}$ & $13,2 \mathrm{~b}$ & $15,1 \mathrm{a}$ & $14,3 \mathrm{a}$ \\
\hline NFG & $15,0 \mathrm{a}$ & $13,1 \mathrm{a}$ & $15,0 \mathrm{a}$ & $13,7 \mathrm{a}$ & $14,0 \mathrm{a}$ & $14,6 \mathrm{a}$ \\
\hline NGF & $30,2 \mathrm{a}$ & 24,9 a & $30,9 \mathrm{a}$ & $27,8 \mathrm{a}$ & $31,4 \mathrm{a}$ & $30,9 \mathrm{a}$ \\
\hline DS & $9,7 \mathrm{c}$ & $23,4 \mathrm{~b}$ & $10,2 \mathrm{c}$ & $24,6 \mathrm{~b}$ & $11,1 \mathrm{c}$ & 25,9 a \\
\hline UMI & $18,9 \mathrm{a}$ & $12,9 \mathrm{~b}$ & $18,5 \mathrm{a}$ & $12,8 \mathrm{~b}$ & $17,7 \mathrm{a}$ & $12,8 \mathrm{~b}$ \\
\hline LG & $8,4 \mathrm{a}$ & $8,1 \mathrm{a}$ & $8,1 \mathrm{a}$ & $8,5 \mathrm{a}$ & $8,0 \mathrm{a}$ & $8,9 \mathrm{a}$ \\
\hline $\mathrm{CG}$ & $3,9 \mathrm{a}$ & $3,6 \mathrm{a}$ & $4,1 \mathrm{a}$ & $3,8 \mathrm{a}$ & $4,0 \mathrm{a}$ & $4,2 \mathrm{a}$ \\
\hline AG & $10,4 \mathrm{a}$ & $9,6 \mathrm{a}$ & $10,6 \mathrm{a}$ & $10,2 \mathrm{a}$ & $10,3 \mathrm{a}$ & $10,7 \mathrm{a}$ \\
\hline PGPL & $102,2 \mathrm{a}$ & $70,4 \mathrm{c}$ & $110,4 \mathrm{a}$ & $87,5 \mathrm{~b}$ & 110,9 a & $101,2 \mathrm{a}$ \\
\hline
\end{tabular}

Médias seguidas de mesmas letras, na linha, não apresentam diferença significativa a 5\% de significância pelo teste de Scott-Knott. 
Segundo Carvalho et al. (2011), diversas características são afetadas pelo ambiente, além de existir a interação entre genótipo e ambiente, capaz de influenciar no desempenho de cultivares. Tais afirmativas podem explicar a redução da média, se comparadas aos demais ambientes na primeira época, para a maioria das características no ambiente 81 , onde, apesar do aumento na dose de $\mathrm{N}$ em cobertura, os genótipos não conseguiram expressar seu maior potencial para as características avaliadas.

Por estar diretamente ligado ao processo de divisão celular e ao processo fotossintético, o $\mathrm{N}$ influenciou no aumento da altura de plantas e de espigas, visto que, em condições adequadas de fornecimento de tal nutriente, as plantas têm o crescimento da área foliar e do sistema radicular favorecidos (Carvalho et al., 2011).

As características, NFG, NGF, LG, CG e AG não apresentaram diferença estatística para os diferentes ambientes e, em sua maioria, nota-se o comportamento crescente seguindo as doses de $\mathrm{N}$ em cobertura, o que mostra o papel fundamental deste nutriente para a formação dos grãos de milho na espiga. Costa et al. (2012) observaram comportamento semelhante para os componentes número de fileiras de grãos e número de grãos por fileira.

Observa-se que as características meteorológicas (Figura 1) não foram capazes de influenciar negativamente a segunda época de semeadura, uma vez que, para a maioria das características, não houve diferença estatística entre os ambientes quando comparados à primeira época de semeadura.

As medidas de dissimilaridade genética, estimadas a partir da distância de Mahalanobis, apresentaram elevada magnitude $(4,8$ a 79,2), indicando a presença de variabilidade genética entre os genótipos (Tabela 3 ). O auxílio para a escolha dos genitores a serem utilizados em futuros cruzamentos pode se dar através da análise da distância genética, o que possibilita, além da economia de tempo, a economia de mão-de-obra e de recursos financeiros (Dotto et al., 2010; Rotili et al., 2012; Santos et al., 2015; Silva et al., 2015).

A combinação entre os genótipos 7 e 10 foi a mais divergente $\left(D^{2}=79,2\right)$, seguida pela combinação entre 9 e $10\left(D^{2}=78,8\right)$ (Tabela 1). A menor distância foi obtida entre os genótipos 3 e 11 e entre 2 e $3\left(D^{2}=4,8\right)$. Quanto menor a distância entre indivíduos, maior a similaridade genética entre os mesmos, fator capaz de reduzir a probabilidade de sucesso para obtenção de híbridos com alto grau de heterose (Rotili et al., 2012; Santos et al., 2014).

Entre as maiores distâncias encontradas, o genótipo 10 esteve presente na maioria das combinações, fato que pode o indicar como genótipo mais divergente, relacionando-se com maior potencial para futuros cruzamentos.

A heterose é o fenômeno que proporciona grande produtividade em híbridos provenientes do cruzamento de parentais que exibem alta divergência entre si (Paterniani et al., 2008).

$\mathrm{Na}$ escolha de genitores para cruzamentos, deve-se considerar se estes apresentam bom rendimento na característica que se deseja melhorar (Silva et al., 2015), além da dissimilaridade entre os mesmos. Assim, os genótipos 8,10 e 12, por apresentarem características desejáveis e dissimilaridade genética, podem proporcionar efeito heterótico elevado após hibridações.

Ao se utilizar o método de otimização de Tocher (Rao, 1952), baseado na dissimilaridade obtida por meio da distância de Mahalanobis, foi possível observar a distribuição dos genótipos avaliados em quatro grupos distintos (Tabela 4). No grupo I, ficaram seis genótipos $(3,11,2,6,5$ e 4$)$ geneticamente similares. O grupo II, representado por três genótipos (GEN 10, GEN 12 e GEN 8). O grupo III, representado por dois genótipos (7 e 9). No grupo IV houve a presença de apenas um genótipo (GEN 1).

Tabela 3. Estimativas de dissimilaridade genética de 12 genótipos de milho, considerando 16 características agronômicas, em ensaios de semeadura tardia. Palmas-TO, 2014.

\begin{tabular}{|c|c|c|c|c|c|c|c|c|c|c|c|}
\hline Genótipos & 2 & 3 & 4 & 5 & 6 & 7 & 8 & 9 & 10 & 11 & 12 \\
\hline 1 & 21,7 & 27,9 & 45,7 & 32,9 & 32,8 & 69,2 & 46,4 & 41,2 & 51,4 & 27,2 & 28,8 \\
\hline 2 & & 4,8 & 19,5 & 18,9 & 11,7 & 30,2 & 23,1 & 22,3 & 31,9 & 7,4 & 14,6 \\
\hline 3 & & & 19,7 & 17,0 & 11,1 & 24,2 & 25,5 & 22,1 & 42,5 & 4,8 & 20,7 \\
\hline 4 & & & & 6,5 & 16,7 & 24,0 & 31,7 & 36,2 & 49,8 & 14,7 & 36,8 \\
\hline 5 & & & & & 19,6 & 37,5 & 20,8 & 42,0 & 39,9 & 10,0 & 28,3 \\
\hline 6 & & & & & & 15,7 & 33,7 & 12,5 & 57,8 & 16,9 & 30,1 \\
\hline 7 & & & & & & & 64,6 & 18,6 & 79,2 & 35,5 & 51,9 \\
\hline 8 & & & & & & & & 67,6 & 18,5 & 12,6 & 16,5 \\
\hline 9 & & & & & & & & & 78,8 & 35,3 & 42,5 \\
\hline 10 & & & & & & & & & & 27,9 & 10,7 \\
\hline 11 & & & & & & & & & & & 14,4 \\
\hline
\end{tabular}


Tabela 4. Agrupamento de 12 genótipos, pelo método de Tocher, com base na distância generalizada de Mahalanobis $\left(\mathrm{D}^{2}\right)$, considerando 16 características agronômicas, em ensaios de semeadura tardia. Palmas-TO, 2014.

\begin{tabular}{cc}
\hline Grupo & Genótipos \\
\hline I & $3,11,2,6,5$ e 4 \\
II & 10,12 e 8 \\
III & 7 e 9 \\
IV & 1 \\
\hline
\end{tabular}

Grupos formados por apenas um indivíduo indicam a maior divergência deste em relação aos demais, o que facilita a projeção dos trabalhos de melhoramento, encontrando-se genótipos distintos para futuros cruzamentos (Rotili et al., 2012). É possível notar que as médias estatísticas dos genótipos para as características avaliadas se assemelham para aqueles que se encontram no mesmo grupo (Tabela 1). Dentro dos programas de melhoramento, a formação dos grupos é primordial para a escolha de genitores promissores, pois os novos materiais que serão obtidos devem ser escolhidos na magnitude de suas dissimilaridades e no potencial "per $s e$ " dos genitores (Martins et al., 2012).

Os genótipos 8, 10 e 12 ficaram no mesmo grupo e também apresentaram maiores médias estatísticas, portanto, apesar do potencial "per se", não são promissores entre si. $\mathrm{O}$ genótipo 7 mostrou-se divergente em relação a estes, foi componente de grupo distinto, e, ainda, apresentou boas médias estatísticas. Portanto, combinações entre os genótipos 7 e 8, 7 e 10 e 7 e 12 podem ser utilizadas em possíveis cruzamentos.

A dissimilaridade intergrupos (Tabela 5), obtida pelo método de otimização de Tocher, permite distinguir entre os grupos formados quais são mais divergentes geneticamente (Rotili et al., 2012; Santos et al., 2015).

As maiores distâncias médias intergrupos foram obtidas entre os grupos III e II $(64,10)$ e entre os grupos IV e III $(55,20)$. Por outro lado, as menores distâncias foram obtidas entre os grupos III e I $(28,13)$ e entre os grupos II e I $(30,1)$. As maiores distâncias intergrupos reforçam o fato de que genótipos em grupos distintos são divergentes. Assim, os grupos que apresentam maior distância entre si devem conter genótipos mais divergentes (Silva et al., 2015). A maior distância observada foi entre os grupos III e II, onde estão os genótipos 7 e 10, que apresentaram a maior distância $\mathrm{D}^{2}$ (Tabela 3).

Os genótipos 7 e 10 apresentaram médias classificadas em grupo estatístico superior para as seguintes características em comum: NFG, NGF, DS, LG, CG e AG. Agrama (1996) afirma que o número de grãos por espiga e o tamanho de grãos são características potenciais para elevação do rendimento na criação de linhas superiores de milho.

Dentre as 16 características avaliadas, as que mais contribuíram para a divergência genética foram MECP $(19,06 \%)$, AP $(17,25 \%)$ e AE $(10,44 \%)$. E as de menor contribuição foram AG $(0,28 \%)$, LG $(0,85 \%)$ e NFG $(1,26 \%$ ) (Tabela 6). O grande interesse na avaliação da importância relativa dos caracteres reside na possibilidade de se utilizar apenas as características que mais contribuíram para discriminar os genótipos, reduzindo, dessa forma, mão-de-obra, tempo e custos despendidos na experimentação (Silva et al., 2015).

Altura de planta e espiga são características avaliadas por vários autores na avaliação da divergência genética, apresentando contribuição média de 12,67 e $17,33 \%$, respectivamente (Rotili et al., 2015). A produtividade de grãos por planta, apesar da pouca contribuição relativa neste trabalho, é a característica de maior importância econômica para a cultura do milho.

Enfim, Cruz et al. (2011) determinam que os estudos que caracterizam a divergência genética são importantes para o conhecimento da variabilidade genética existente nos bancos de germoplasmas, possibilitando o monitoramento, auxiliando na identificação de possíveis duplicatas e fornecendo parâmetros para a escolha de progenitores que, ao serem cruzados, possibilitem maior efeito heterótico, aumentando as chances de obtenção de genótipos superiores em gerações segregantes.

Tabela 5. Distâncias médias entre grupos formados pela análise de divergência genética em 12 genótipos de milho. Palmas-TO, 2014.

\begin{tabular}{cccc}
\hline Grupos & I & II & III \\
II & 30,1 & & \\
III & 28,1 & 64,1 & \\
IV & 31,4 & 42,2 & 55,2 \\
\hline
\end{tabular}


Tabela 6. Contribuição relativa dos caracteres para diversidade genética pelo método de Singh (1981) baseada na distância generalizada de Mahalanobis, de 12 genótipos de milho. Palmas-TO, 2014.

\begin{tabular}{cc}
\hline Variável & Valor $(\%)$ \\
\hline Altura da planta - AP & 17,25 \\
Altura da espiga - AE & 10,44 \\
Número de folhas totais na planta - NF & 7,96 \\
Número de folhas acima da espiga principal - NFAE & 3,56 \\
Massa da espiga com palha - MECP & 19,06 \\
Massa da espiga sem palha - MESP & 8,03 \\
Diâmetro da espiga - DE & 2,54 \\
Comprimento da espiga - CE & 1,32 \\
Número de fileiras de grãos - NFG & 1,26 \\
Número de grãos por fileira - NGF & 7,97 \\
Diâmetro do sabugo - DS & 3,35 \\
Umidade - UMI & 8,73 \\
Largura do grão - LG & 0,85 \\
Comprimento do grão - CG & 3,68 \\
Altura do grão - AG & 0,28 \\
Produtividade de grãos por planta - PGPL & 3,73 \\
\hline
\end{tabular}

\section{Conclusões}

As características massa da espiga com palha, altura da planta e altura da espiga foram as que mais contribuíram para a divergência genética.

As combinações promissoras para recombinação foram entre os genótipos 7 e 8,7 e 10 e 7 e 12 .

\section{Referências Bibliográficas}

Agrama, H.A.S., 1996. Sequential path analysis of grain yield and its components in maize. Plant Breeding, 115(5), 343-346.

Albuquerque, C.J.B., Pinho, R.G.V., Borges, I.D., Souza Filho, A.X., Fiorini, I.V.A, 2008. Desempenho de híbridos experimentais e comerciais de milho para produção de milho verde. Ciência e Agrotecnologia, 32(3), 768-775.

Alvarez, C.G.D., Pinho, R.G.V., Borges, I.D., 2006. Avaliação de características agronômicas e de produção de forragem e grãos de milho em diferentes densidades de semeadura e espaçamentos entre linhas. Ciência e Agrotecnologia, 30(3), 402-408.

Alvim, K.R.T., Brito, C.H., Brandão, A.M., Gomes, L.S., Lopes, M.T.G., 2010. Quantificação da área foliar e efeito da desfolha em componentes de produção de milho. Ciência Rural, 40(5), 1017-1022.

Barros, H.B., Fidelis, R.R., Melo, A.V., Capone, A., Sediyama, T., 2012. Adaptabilidade e estabilidade de genótipos de soja por meio de métodos uni e multivariado. Journal of Biotechnology and Biodiversity, 3(2), 49-58.

Borém, A., Galvão, J.C.C., Pimentel, M.A., 2017. Milho do plantio à colheita, segunda ed. Editora UFV, Viçosa.

Carvalho, E.V., Afférri, F.S., Peluzio, J.M., Dotto, M.A., Cappellesso, R.B., Melo, A.V., 2011. Desempenho agronômico e divergência genética na seleção de linhagens S5 de milho. Bioscience Journal, 27(5), 794-797.

Coimbra, R.R., Miranda, G.V., Cruz, C.D., Melo, A.V., Eckert, F.R., 2010. Caracterização e divergência genética de populações de milho resgatadas do Sudeste de Minas Gerais. Revista Ciência Agronômica, 41(1), 159-166.

Costa, N.R., Andreotti, M., Gameiro, R.A., Pariz, C.M., Buzetti, S., Lopes, K.S.M., 2012. Adubação nitrogenada no consórcio de milho com duas espécies de braquiária em sistema plantio direto. Pesquisa Agropecuária Brasileira, 47(8), 1038-1047.

Cruz, C.D., Ferreira, F.M., Pessoni, L.A., 2011. Biometria aplicada ao estudo da diversidade genética. Suprema, Viçosa.

Cruz, C.D., Regazzi, A.J., Carneiro, P.C.S., 2012. Modelos biométricos aplicados ao melhoramento genético, quarta ed. Editora UFV, Viçosa.

Dotto, M.A., Afferri, F.S., Peluzio, J.M., Melo, A.V., Carvalho, E.V., 2010. Divergência genética entre cultivares comerciais de milho em baixas altitudes no Tocantins, safra 2007/2008. Revista Ciência Agronômica, 41(4), 630-637.

Fornasieri Filho, D., 2007. Manual da cultura do milho. Funep: Jaboticabal.

Goes, R.J., Rodrigues, R.A.F., Arf, O., Vilela, R.G., 2012. Nitrogênio em cobertura para o milho (Zea mays L.) em sistema plantio direto na safrinha. Revista Brasileira de Milho e Sorgo, 11(2), 169-177.

Lins, F.J.A., Ferreira, P.V., Assunção, M.C., Santos, D.F., Carvalho, A.P.V., Santos, N.E.A., 2017. Crescimento de genótipos experimentais de milho em função de doses crescentes de nitrogênio. Ciência Agrícola, 15(2), 19-27.

Martins, E.C.A., Peluzio, J.M., Coimbra, R.R., Junior, W.P.O., 2012. Variabilidade fenotípica e divergência genética em 
clones de batata doce no estado do Tocantins. Revista Ciência Agronômica, 43(4), 691-697.

Paterniani, M.E.A.G.Z., Guimarães, O.S., Lüders, R.R., Gallo, P.B., Souza, A.P., Laborda, P.R., Oliveira, K.M., 2008. Capacidade combinatória, divergência genética entre linhagens de milho e correlação com heterose. Bragantia, 67(3), 639-648.

Pizolato Neto, A., Camargos, A.E.V., Valeriano, T.B., Sgobi, M.A., Santana, M.J., 2016. Doses de nitrogênio para cultivares de milho irrigado. Nucleus, 13(1), 87-96.

Rao, C.R., 1952. Advanced statistical methods in biometric research. John Willey \& Sons, New York.

Ribeiro, A.C., Guimarães, P.T.G., Alvarez, V.V.H., 1999. Recomendações para o uso de corretivos e fertilizantes em Minas Gerais - $5^{\text {a }}$ Aproximação. Editora UFV, Viçosa.

Rotili, E.A., Afférri, F.S., Peluzio, J.M., Pimenta, R.S., Carvalho, E.V., 2015. Importância das características morfológicas e agronômicas no estudo da biodiversidade genética em milho. Revista Verde, 10(5), 59-65.

Rotili, E.A., Cancellier, L.L., Dotto, M.A., Peluzio, J.M., Carvalho, E.V., 2012. Divergência genética em genótipos de milho, no estado do Tocantins. Revista Ciência Agronômica, 43(3), 516-521.
Santos, W.F., Afférri, F.S., Peluzio, J.M., 2015. Eficiência ao uso do nitrogênio e biodiversidade em genótipos de milho para teor de óleo. Enciclopédia Biosfera, 11(21), 2916-2925.

Santos, W.F., Peluzio, J.M., Afférri, F.S., Sodré, L.F., Santos, D.S., Farias, T.C.M., 2014. Variabilidade genética e eficiência de uso do nitrogênio em genótipos de milho para teor de óleo. Revista de Ciências Agrárias, 57(3), 312-317.

Scott, A., Knott, M., 1974. Cluster analysis method for grouping means in analysis of variance. Biometrics, 30(3), 507-512.

Silva, K.C.L., Silva, K.P., Carvalho, E.V., Rotili, E.A., Afférri, F.S., Peluzio, J.M., 2015. Divergência genética de genótipos de milho com e sem adubação nitrogenada em cobertura. Revista Agro@mbiente On-line, 9(2), 102-110.

Simon, G.A., Kamada, T., Moiteiro, M., 2012. Divergência genética em milho de primeira e segunda safra. Semina: Ciências Agrárias, 33(2), 449-458.

Singh, D., 1981. The relative importance of characters affecting genetic divergence. Indian Journal of Genetics and Plant Breeding, 41(2), 237-245. 